\title{
Frasier syndrome
}

INSERM

\section{Source}

INSERM. (1999). Orphanet: an online rare disease and orphan drug data base. Frasier syndrome. ORPHA:347

Frasier syndrome is characterised by the association of male pseudohermaphrodism and glomerular nephropathy. This syndrome is associated with a high risk of developing gonadoblastoma. 